\title{
07.2
}

\section{Гетероструктуры квантово-каскадных лазеров с неселективным заращиванием методом газофазной эпитаксии}

\author{
(C) А.В. Бабичев ${ }^{1}$, А.Г. Гладышев ${ }^{2}$, Д.В. Денисов ${ }^{3}$, В.В. Дюделев ${ }^{1}$, Д.А. Михайлов ${ }^{1}$, С.О. Слипченко ${ }^{1}$, \\ А.В. Лютецкий ${ }^{1}$, Л.Я. Карачинский ${ }^{1,2,4}$, И.И. Новиков ${ }^{1,2,4}$, А.Ю. Андреев ${ }^{5}$, И.В. Яроцкая ${ }^{5}$, \\ К.А. Подгаецкий ${ }^{5}$, А.А. Мармалюк ${ }^{5}$, А.А. Падалица ${ }^{5}$, М.А. Ладугин ${ }^{5}$, Н.А. Пихтин ${ }^{1}$, \\ Г.С. Соколовский ${ }^{1}$, А.Ю. Егоров ${ }^{4}$ \\ ${ }^{1}$ Физико-технический институт им. А.Ф. Иофрфе РАН, Санкт-Петербург, Россия \\ ${ }^{2} \mathrm{OOO} \mathrm{„Коннектор} \mathrm{Оптикс“,} \mathrm{Санкт-Петербург,} \mathrm{Россия}$ \\ ${ }^{3}$ Санкт-Петербургский государственный электротехнический университет „ЛЭТИ“, Санкт-Петербург, Россия \\ ${ }^{4}$ Университет ИТМО, Санкт-Петербург, Россия \\ 5 АО „НИИ „Полюс“ им М.Ф. Стельмаха“, Москва, Россия \\ E-mail: a.babichev@mail.ioffe.ru
}

Поступило в Редакцию 3 сентября 2021 г.

В окончательной редакции 23 сентября 2021 r.

Принято к публикации 24 сентября 2021 г.

\begin{abstract}
Показана возможность создания гетероструктур квантово-каскадных лазеров спектрального диапазона $4.6 \mu \mathrm{m}$ методом молекулярно-пучковой эпитаксии с неселективным заращиванием методом газофазной эпитаксии из металлоорганических соединений. Активная область лазера была сформирована на основе гетеропары твердых растворов $\mathrm{In}_{0.67} \mathrm{Ga}_{0.33} \mathrm{As} / \mathrm{In}_{0.36} \mathrm{Al}_{0.64} \mathrm{As}$. Слои фосфида индия выполняли функцию обкладок волновода. Результаты исследования карт поверхностных дефектов гетероструктур квантовокаскадных лазеров, рентгеноструктурного анализа позволяют сделать вывод о высоком структурном качестве гетероструктур и низкой оценочной величине среднеквадратичной поверхностной шероховатости, не превышающей $0.7 \mathrm{~nm}$. Лазеры с четырьмя сколотыми гранями демонстрируют генерацию при комнатной температуре с относительно низкой плотностью порогового тока порядка $1 \mathrm{kA} / \mathrm{cm}^{2}$.
\end{abstract}

Ключевые слова: сверхрешетки, квантово-каскадный лазер, эпитаксия, фосфид индия.

DOI: 10.21883/PJTF.2021.24.51800.19014

При создании мощных квантово-каскадных лазеров (ККЛ), работающих в непрерывном режиме токовой накачки, актуальной проблемой, требующей решения, является отвод тепла от гетероструктуры как в горизонтальном, так и в вертикальном направлениях. Для отвода тепла вдоль слоев гетероструктуры применяют технику заращивания полоскового лазера полуизолирующими слоями фосфида индия [1]. Для теплоотвода в вертикальном направлении используют толстые слои легированного InP наряду с монтажом кристалла ККЛ на теплоотвод на основе AlN или алмаза [1,2]. При этом исторически для увеличения фактора перекрытия оптической моды со слоями активной области (Г-фактора) при формировании обкладок волновода используют тонкие слои InGaAs. Однако детальный расчет, проведенный методом конечных элементов, показывает, что использование дополнительных слоев InGaAs в слоях обкладок волновода приводит к слабому увеличению Г-фактора с 64 до $65 \%$ [3,4]. В то же время теплопроводность тройного твердого раствора InGaAs в 12 раз ниже теплопроводности InP [3]. Таким образом, для повышения эффективности теплоотвода ККЛ в вертикальном направлении более предпочтительным является использование обкладок волновода, полностью сформированных на основе фосфида индия $[2,3]$.
Поскольку метод молекулярно-пучковой эпитаксии (МПЭ) позволяет создавать более резкие гетерограницы, чем метод газофазной эпитаксии из металлоорганических соединений (МОГФЭ) [5], для реализации лазеров с рекордными характеристиками комбинируют две технологии эпитаксии $[1,6,7]$ : для выращивания активной области используют метод МПЭ, а для формирования слоев фосфида индия, образующих верхнюю обкладку волновода, используют метод МОГФЭ.

В настоящей работе представлены результаты по неселективному заращиванию методом МОГФЭ гетероструктур ККЛ спектрального диапазона $4.6 \mu \mathrm{m}$, выращенных методом МПЭ.

Гетероструктура ККЛ была выращена на подложке InP c ориентацией (001) компанией „Коннектор Оптикс“ на промышленной установке молекулярно-пучковой эпитаксии Riber 49 [8,9]. Активная область двух типов гетероструктур ККЛ сформирована из 30 и 45 каскадов на основе гетеропары твердых растворов $\mathrm{In}_{0.67} \mathrm{Ga}_{0.33} \mathrm{As} / \mathrm{In}_{0.36} \mathrm{Al}_{0.64} \mathrm{As}$ [10]. После выращивания слоев активной области формировался слой InP толщиной $100 \mathrm{~nm}$ (уровень легирования $n=1.0 \cdot 10^{17} \mathrm{~cm}^{-3}$ ). После предварительной характеризации структурного качества в чистых помещениях производилось неселективное заращивание гетероструктуры методом МОГФЭ. В качестве исходных реагентов использовались 
Плотность нормальных и овальных дефектов, а также величина параметра haze для гетероструктур ККЛ после заращивания методом МОГФЭ

\begin{tabular}{c|c|c|c|c}
\hline $\begin{array}{c}\text { Число } \\
\text { каскадов } \\
\text { в структуре }\end{array}$ & $\begin{array}{c}\text { Плотность } \\
\text { нормальных } \\
\text { дефектов, } \mathrm{cm}^{-2}\end{array}$ & $\begin{array}{c}\text { Наzе в диапазоне } \\
0.6-10 \mu \mathrm{m}^{2} / \delta, \\
\mathrm{ppm} / \mathrm{nm}\end{array}$ & $\begin{array}{c}\text { Плотность } \\
\text { овальных } \\
\text { дефектов, } \mathrm{cm}^{-2}\end{array}$ & $\begin{array}{c}\text { Haze в диапазоне } \\
10-250 \mu \mathrm{m}^{2} / \delta, \\
\mathrm{ppm} / \mathrm{nm}\end{array}$ \\
\hline 30 & 253 & $147 / 0.7$ & 104 & $114 / 0.6$ \\
30 & 181 & $127 / 0.7$ & 49 & $96 / 0.6$ \\
30 & 165 & $130 / 0.7$ & 53 & $103 / 0.6$ \\
45 & 222 & $128 / 0.7$ & 65 & $105 / 0.6$ \\
45 & 191 & $136 / 0.7$ & 47 & $110 / 0.6$ \\
45 & 161 & $120 / 0.6$ & 56 & $94 / 0.6$ \\
\end{tabular}

триметилгаллий, триметилиндий, фосфин и арсин. Температура роста составляла $600-670^{\circ} \mathrm{C}$. Образцы перед заращиванием подвергались предварительному отжигу в атмосфере фосфина $\left(\mathrm{PH}_{3}\right)$ при температуре $600^{\circ} \mathrm{C}$ в течение $5 \mathrm{~min}$. Типичная скорость роста для InP составляла $1.8 \mu \mathrm{m} / \mathrm{h}$, для $\mathrm{In}_{0.53} \mathrm{Ga}_{0.47} \mathrm{As}-0.3 \mu \mathrm{m} / \mathrm{h}$. Таким образом, на поверхности гетероструктуры, выращенной методом МПЭ, с помощью метода МОГФЭ были сформированы слои верхней обкладки волновода суммарной толщиной $2.9 \mu \mathrm{m}$ на основе фосфида индия (с переменным уровнем легирования в диапазоне $\left.1.0 \cdot 10^{17}-3.0 \cdot 10^{18} \mathrm{~cm}^{-3}\right)$. Толщина контактного слоя $\operatorname{In}_{0.53} \mathrm{Ga}_{0.47} \mathrm{As}$ c уровнем легирования $2.5 \cdot 10^{19} \mathrm{~cm}^{-3}$ составила $200 \mathrm{~nm}$. Формирование кристалла 4-сколотых ККЛ проводилось по методике, аналогичной описанной ранее [11]. Размеры 4-сколотых лазеров составили $360 \times 360$ и $340 \times 340 \mu \mathrm{m}$ для структур ККЛ с активной областью на основе 30 и 45 каскадов соответственно. Монтаж лазерного кристалла проводился эпитаксиальной поверхностью вниз на медный теплоотвод при помощи индиевого припоя.

Структурное качество гетероструктуры, а также толщина слоев в каскадах оценивались методом рентгеновской дифрактометрии. Измерения спектров рентгеновской дифракции были проведены вблизи симметричного рефлекса (004) InP на дифрактометре PANalytical X'PertPro в параллельной геометрии пучка рентгеновского излучения.

Исследование карт поверхностных дефектов гетероструктур ККЛ проводилось на автоматизированной системе контроля состояния поверхности и определения плотности дефектов подложек и структур Surfscan KLA Tencor. Плотность нормальных дефектов (с размерами в диапазоне $0.6-10 \mu \mathrm{m}^{2}$ ) для структур, включающих 30 каскадов, перед процессом заращивания методом МОГФЭ находилась в диапазоне $57-74 \mathrm{~cm}^{-2}$, а плотность овальных дефектов (с размерами в диапазоне $10-250 \mu \mathrm{m}^{2}$ ) не превышала $5 \mathrm{~cm}^{-2}$. Величина параметра haze, характеризующего шероховатость, в диапазоне $0.6-10 \mu \mathrm{m}^{2}$ не превысила значения $16 \mathrm{ppm}$, что соответствует оценочной величине среднеквадратичной поверхностной шероховатости $\delta$, не превышающей $0.2 \mathrm{~nm}$. Оценка параметра $\delta$ проведена с использованием выра- жения [12]:

$$
\delta=(\lambda / 4 \cdot \pi)\left(H / R_{0}\right)^{0.5},
$$

где $R_{0}-$ коэффициент отражения материала, $H-$ величина haze, $\lambda$ - длина волны накачки в системе контроля состояния поверхности и определения плотности дефектов подложек и структур Surfscan KLA Tencor, которая составила $488 \mathrm{~nm}$. Величина параметра haze в диапазоне $10-250 \mu \mathrm{m}^{2}$ близка к нулевому значению, что характеризует отсутствие среднеквадратичной поверхностной шероховатости $\delta$.

Плотность нормальных дефектов для структур, включающих 45 каскадов, перед процессом заращивания методом МОГФЭ находилась в диапазоне $81-88 \mathrm{~cm}^{-2}$, а плотность овальных дефектов не превышала $10 \mathrm{~cm}^{-2}$. Величина параметра haze в диапазоне $0.6-10 \mu \mathrm{m}^{2}$ не превысила значения $20 \mathrm{ppm}$, что соответствует оценочной величине $\delta$, не превышающей $0.3 \mathrm{~nm}$. Величина параметра haze в диапазоне $10-250 \mu \mathrm{m}^{2}$ не превысила $2 \mathrm{ppm}$, что соответствует оценочной величине $\delta$, не превышающей $0.1 \mathrm{~nm}$.

Результаты оценки плотности дефектов после заращивания представлены в таблице.

Плотность нормальных дефектов для всех исследованных гетероструктур после процесса заращивания методом МОГФЭ не превышала $260 \mathrm{~cm}^{-2}$, а плотность овальных дефектов - $104 \mathrm{~cm}^{-2}$. Величина параметра haze в диапазоне $0.6-10 \mu \mathrm{m}^{2}$ не превысила $150 \mathrm{ppm}$, что соответствует оценочной величине $\delta$, не превышающей $0.7 \mathrm{~nm}$. Величина параметра haze в диапазоне $10-250 \mu \mathrm{m}^{2}$ не превысила $115 \mathrm{ppm}$, что соответствует оценочной величине $\delta$, не превышающей $0.6 \mathrm{~nm}$. Ранее для гетероструктур ККЛ спектрального диапазона $4.6 \mu \mathrm{m}$, полностью выращенных методом МПЭ [10], плотность нормальных дефектов не превышала $140 \mathrm{~cm}^{-2}$, а плотность овальных дефектов $-25 \mathrm{~cm}^{-2}$. Величина параметра haze в диапазоне $0.6-10 \mu \mathrm{m}^{2}$ не превышала 100 ppm, что соответствует оценочной величине $\delta$, не превышающей $0.6 \mathrm{~nm}$. Величина параметра haze в диапазоне $10-250 \mu \mathrm{m}^{2}$ не превышала $66 \mathrm{ppm}$, что соответствует оценочной величине $\delta$, не превышающей $0.5 \mathrm{~nm}$. 

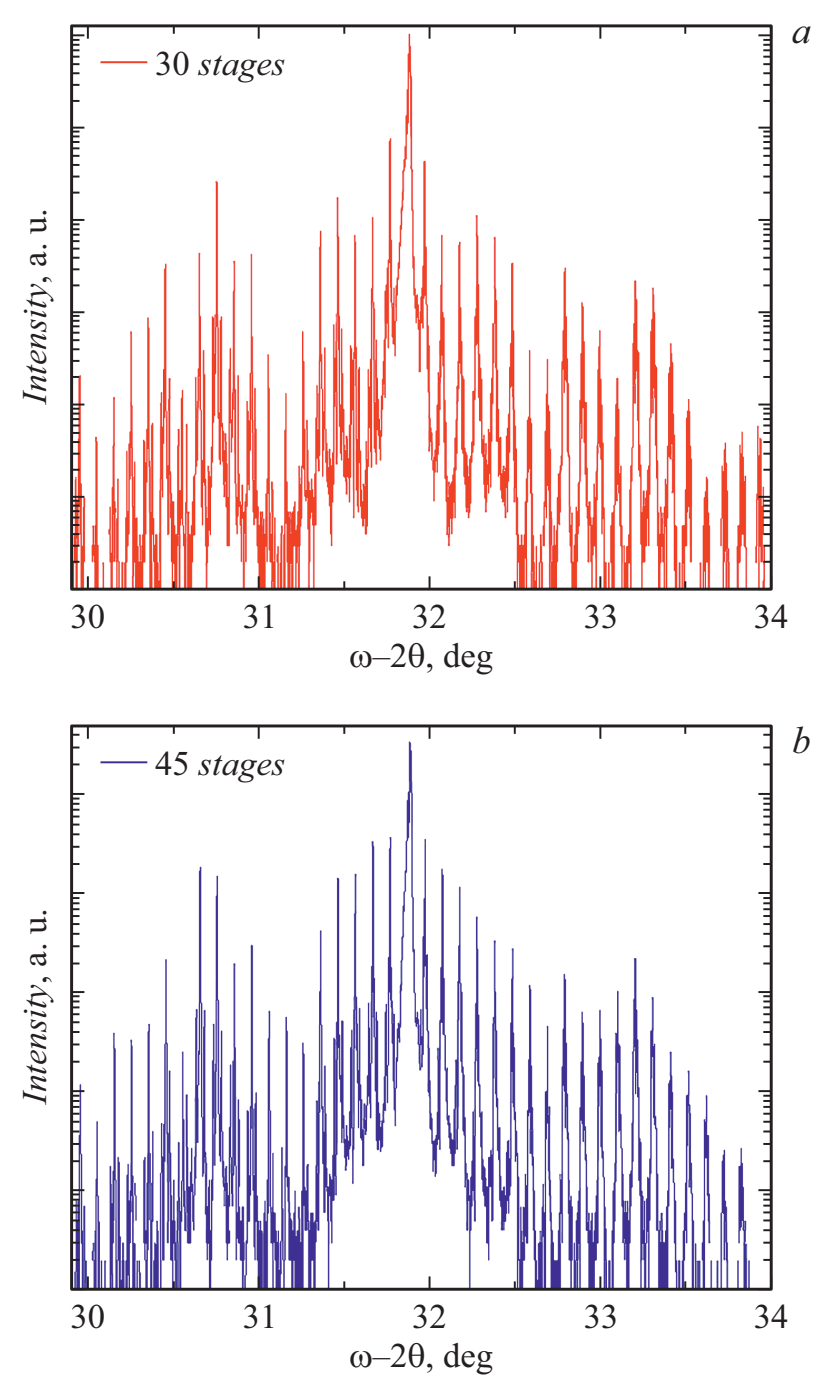

Рис. 1. Рентгенодифракционные кривые гетероструктур ККЛ с неселективным заращиванием методом МОГФЭ. $a-$ ККЛ с активной областью на основе 30 каскадов, $b-$ ККЛ с активной областью на основе 45 каскадов.

На рис. 1 представлены экспериментальные кривые качания гетероструктур ККЛ с активной областью на основе 30 и 45 каскадов. Измерения проведены после процесса заращивания методом МОГФЭ. На рентгенодифракционных кривых наблюдается полное совпадение нулевого пика сателлитной структуры с положением пика от подложки InP. Данный факт свидетельствует о точном соответствии химического состава эпитаксиальных слоев заданным значениям, приведенным в ростовой спецификации. На кривых качания наблюдается большое количество (порядка 40) пиков-сателлитов высоких порядков, характерных для периодической структуры каскадов. Анализ кривых дает довольно малое значение средней ширины на полувысоте (FWHM) пиков-сателлитов $13 \pm 2^{\prime \prime}$, что свидетельствует о высокой однородности состава и толщин различных каскадов в полученных гетероструктурах и соотносится с результатами [10].
На основании положения 20 пиков-сателлитов была проведена оценка средней толщины периода каскада, которая составила $50.8 \pm 0.2$ и $50.5 \pm 0.4 \mathrm{~nm}$ для гетероструктур ККЛ с активной областью на основе 30 и 45 каскадов соответственно. Таким образом, данные рентгенодифракционного анализа свидетельствуют о высоком структурном совершенстве гетероструктур ККЛ с активными областями, выращенных методом МПЭ с последующим формированием слоев верхней обкладки волновода и контактных слоев методом МОГФЭ.

Характеристики ККЛ исследовались в импульсном режиме. Длительность импульсов накачки составляла $200 \mathrm{~ns}$ при частоте повторения $25 \mathrm{kHz}$. Для получения зависимости интенсивности излучения ККЛ от тока накачки излучение лазера коллимировалось при помощи высокоапертурной линзы и регистрировалось охлаждаемым фотоприемником Vigo PVI-4TE-10.6, подключенным к осциллографу Agilent 54835. Полоса пропускания обоих приборов составляла $1 \mathrm{GHz}$. Параллельная регистрация на осциллографе импульсов фотоответа и импульсов тока накачки позволила получить одновременную запись данных для построения импульсной вольтамперной характеристики, а также зависимости импульсной интенсивности излучения ККЛ от тока накачки. Зависимости импульсной интенсивности излучения, а также вольт-амперные характеристики 4-сколотых ККЛ представлены на рис. 2. Значение пороговой плотности тока составило порядка $1.0 \mathrm{kA} / \mathrm{cm}^{2}$, что соотносится с ранее полученными результатами для ККЛ спектрального диапазона $4.6 \mu \mathrm{m}$, полностью выращенных методом МПЭ [10]. Пороговое напряжение в лазерах составило 7.5-8.0 и $12 \mathrm{~V}$ для ККЛ с активной областью на основе 30 и 45 каскадов соответственно. Регистрация спектров

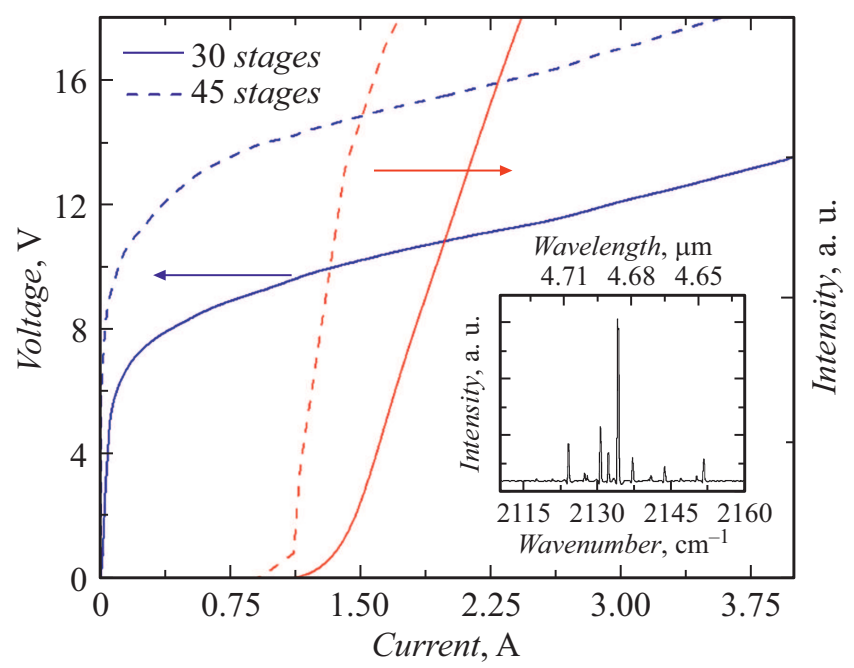

Рис. 2. Вольт-амперные характеристики (левая ось) и зависимости импульсной интенсивности излучения от уровня накачки (правая ось) для 4-сколотых ККЛ с активной областью на основе 30 (сплошные линии) и 45 (штриховые линии) каскадов. На вставке - типичный спектр генерации вблизи порогового значения для ККЛ с активной областью на основе 30 каскадов. 
генерации ККЛ проводилась при помощи вакуумированного фурье-спектрометра BrukerVertex 70v. Типичный спектр лазерной генерации представлен группой оптических мод в спектральном диапазоне 4.65-4.70 $\mu \mathrm{m}$ (см. вставку на рис. 2).

Таким образом, в ходе исследований получены результаты по созданию и изучению характеристик ККЛ спектрального диапазона $4.6 \mu \mathrm{m}$. Комбинирование двух технологий эпитаксии для создания гетероструктур ККЛ позволило реализовать 4-сколотые лазеры, демонстрирующие пороговые плотности тока, сопоставимые с результатами для аналогичных структур ККЛ, полностью выращенных методом МПЭ [10]. С учетом того, что полосковые ККЛ, изготовленные из гетероструктур, полностью выращенных методом МПЭ, демонстрируют высокую выходную оптическую мощность (на уровне $10 \mathrm{~W})[13,14]$, можно сделать вывод о перспективности применения комбинированного подхода в эпитаксии гетероструктур для реализации мощных ККЛ спектрального диапазона $4.6 \mu \mathrm{m}$. При этом увеличение числа каскадов до 45 может дополнительно повысить выходную оптическую мощность в сравнении с ранее представленными результатами [14], что является предметом дальнейших исследований.

\section{Финансирование работы}

Работа выполнена за счет гранта Российского научного фонда (проект № 21-72-30020).

\section{Конфликт интересов}

Авторы заявляют, что у них нет конфликта интересов.

\section{Список литературы}

[1] Q. Lu, S. Slivken, D. Wu, M. Razeghi, Opt. Express, 28 (10), 15181 (2020). DOI: 10.1364/oe.393069

[2] M. Suttinger, R. Kaspi, A. Lyakh, in Mid-infrared optoelectronics, ed. by E. Tournié, L. Cerutti (Woodhead Publ., Sawston, UK, 2020), p. 181-205. DOI: 10.1016/b978-0-08-102709-7.00005-x

[3] P. Figueiredo, M. Suttinger, R. Go, E. Tsvid, C.K.N. Patel, A. Lyakh, Appl. Opt., 56 (31), H15 (2017). DOI: $10.1364 /$ ao. $56.000 \mathrm{~h} 15$

[4] A. Lyakh, M. Suttinger, R. Go, P. Figueiredo, A. Todi, Appl. Phys. Lett., 109 (12), 121109 (2016). DOI: $10.1063 / 1.4963233$

[5] R. Maulini, A. Lyakh, A. Tsekoun, C.K.N. Patel, Opt. Express, 19 (18), 17203 (2011). DOI: 10.1364/oe.19.017203

[6] F. Kapsalidis, M. Shahmohammadi, M.J. Süess, J.M. Wolf, E. Gini, M. Beck, M. Hundt, B. Tuzson, L. Emmenegger, J. Faist, Appl. Phys. B, 124 (6), 107 (2018). DOI: $10.1007 / \mathrm{s} 00340-018-6973-2$

[7] L. Consolino, S. Jung, A. Campa, M. De Regis, S. Pal, J.H. Kim, K. Fujita, A. Ito, M. Hitaka, S. Bartalini, P. De Natale, M.A. Belkin, M.S. Vitiello, Sci. Adv., 3 (9), e1603317 (2017). DOI: $10.1126 /$ sciadv.1603317
[8] А.В. Бабичев, В.В. Дюделев, А.Г. Гладышев, Д.А. Михайлов, А.С. Курочкин, Е.С. Колодезный, В.Е. Бугров, В.Н. Неведомский, Л.Я. Карачинский, И.И. Новиков, Д.В. Денисов, А.С. Ионов, С.О. Слипченко, А.В. Лютецкий, Н.А. Пихтин, Г.С. Соколовский, А.Ю. Егоров, Письма в ЖТФ, 45 (14), 48 (2019). DOI: 10.21883/PJTF.2019.14.48025.17824 [A.V. Babichev, V.V. Dudelev, A.G. Gladyshev, D.A. Mikhailov, A.S. Kurochkin, E.S. Kolodeznyi, V.E. Bougrov, V.N. Nevedomskiy, L.Ya. Karachinsky, I.I. Novikov, D.V. Denisov, A.S. Ionov, S.O. Slipchenko, A.V. Lutetskiy, N.A. Pikhtin, G.S. Sokolovskii, A.Yu. Egorov, Tech. Phys. Lett., 45 (7), 735 (2019).

DOI: $10.1134 / \mathrm{s} 1063785019070174]$.

[9] А.В. Бабичев, А.Г. Гладышев, А.С. Курочкин, В.В. Дюделев, Е.С. Колодезный, Г.С. Соколовский, В.Е. Бугров, Л.Я. Карачинский, И.И. Новиков, Д.В. Денисов, А.С. Ионов, С.О. Слипченко, А.В. Лютецкий, Н.А. Пихтин, А.Ю. Егоров, Письма в ЖТФ, 45 (8), 31 (2019). DOI: 10.21883/PJTF.2019.08.47618.17716 [A.V. Babichev, A.G. Gladyshev, A.S. Kurochkin, V.V. Dudelev, E.S. Kolodeznyi, G.S. Sokolovskii, V.E. Bugrov, L.Ya. Karachinsky, I.I. Novikov, D.V. Denisov, A.S. Ionov, S.O. Slipchenko, A.V. Lyutetskii, N.A. Pikhtin, A.Yu. Egorov, Tech. Phys. Lett., 45 (4), 398 (2019). DOI: $10.1134 / \mathrm{s} 1063785019040205]$.

[10] А.В. Бабичев, А.Г. Гладышев, В.В. Дюделев, Л.Я. Карачинский, И.И. Новиков, Д.В. Денисов, С.О. Слипченко, А.В. Лютецкий, Н.А. Пихтин, Г.С. Соколовский, А.Ю. Егоров, Письма в ЖТФ, 46 (9), 35 (2020). DOI: 10.21883/PJTF.2020.09.49371.18243 [A.V. Babichev, A.G. Gladyshev, V.V. Dudelev, L.Ya. Karachinsky, I.I. Novikov, D.V. Denisov, S.O. Slipchenko, A.V. Lyutetskii, N.A. Pikhtin, G.S. Sokolovskii, A.Yu. Egorov, Tech. Phys. Lett., 46 (5), 442 (2020). DOI: 10.1134/s1063785020050028].

[11] А.Ю. Егоров, А.В. Бабичев, Л.Я. Карачинский, И.И. Новиков, Е.В. Никитина, М. Tchernycheva, А.Н. Софронов, Д.А. Фирсов, Л.Е. Воробьев, Н.А. Пихтин, И.С. Тарасов, ФТП, 49 (11), 1574 (2015). [A.Yu. Egorov, A.V. Babichev, L.Ya. Karachinsky, I.I. Novikov, E.V. Nikitina, M. Tchernycheva, A.N. Sofronov, D.A. Firsov, L.E. Vorobjev, N.A. Pikhtin, I.S. Tarasov, Semiconductors, 49 (11), 1527 (2015). DOI: 10.1134/s1063785020050028].

[12] A. Steinbach, A. Belyaev, B. Pinto, D. Chen, S. Radovanovic, G. Neskovic, H. Yeh, A. Wang, J. Cao, J. Reich, D. Kavaldjiev, P. Dighe, R. Bammi, L. Vintro, D. Bloom, in Be market ready, ed. by U. Subramaniam. Yield management solutions (KLATencor Corporation, San Jose, California, 2006), p. 64-67. Доступно онлайн: https://www.ymsmagazine.com/wpcontent/uploads/summer06.pdf\#page=64 (дата обращения 03.09.2021).

[13] В.В. Дюделев, Д.А. Михайлов, А.В. Бабичев, С.Н. Лосев, Е.А. Когновицкая, А.В. Лютецкий, С.О. Слипченко, Н.А. Пихтин, А.Г. Гладышев, Д.В. Денисов, И.И. Новиков, Л.Я. Карачинский, В.И. Кучинский, А.Ю. Егоров, Г.С. Соколовский, Квантовая электроника, 50 (8), 720 (2020). [V.V. Dudelev, D.A. Mikhailov, A.V. Babichev, S.N. Losev, E.A. Kognovitskaya, A.V. Lyutetskii, S.O. Slipchenko, N.A. Pikhtin, A.G. Gladyshev, D.V. Denisov, I.I. Novikov, L.Ya. Karachinsky, V.I. Kuchinskii, A.Yu. Egorov, G.S. Sokolovskii, Quantum Electron., 50 (8), 720 (2020). DOI: $10.1070 /$ qel17332]. 
[14] В.В. Дюделев, Д.А. Михайлов, А.В. Бабичев,

Г.М. Савченко, С.Н. Лосев, Е.А. Когновицкая,

А.В. Лютецкий, С.О. Слипченко, Н.А. Пихтин,

А.Г. Гладышев, Д.В. Денисов, И.И. Новиков,

Л.Я. Карачинский, В.И. Кучинский, А.Ю. Егоров,

Г.С. Соколовский, Квантовая электроника, 50 (11), 989

(2020). [V.V. Dudelev, D.A. Mikhailov, A.V. Babichev,

G.M. Savchenko, S.N. Losev, E.A. Kognovitskaya,

A.V. Lyutetskii, S.O. Slipchenko, N.A. Pikhtin,

A.G. Gladyshev, D.V. Denisov, I.I. Novikov, L.Ya. Karachinsky,

V.I. Kuchinskii, A.Yu. Egorov, G.S. Sokolovskii, Quantum Electron., 50 (11), 989 (2020). DOI: 10.1070/qel17396]. 